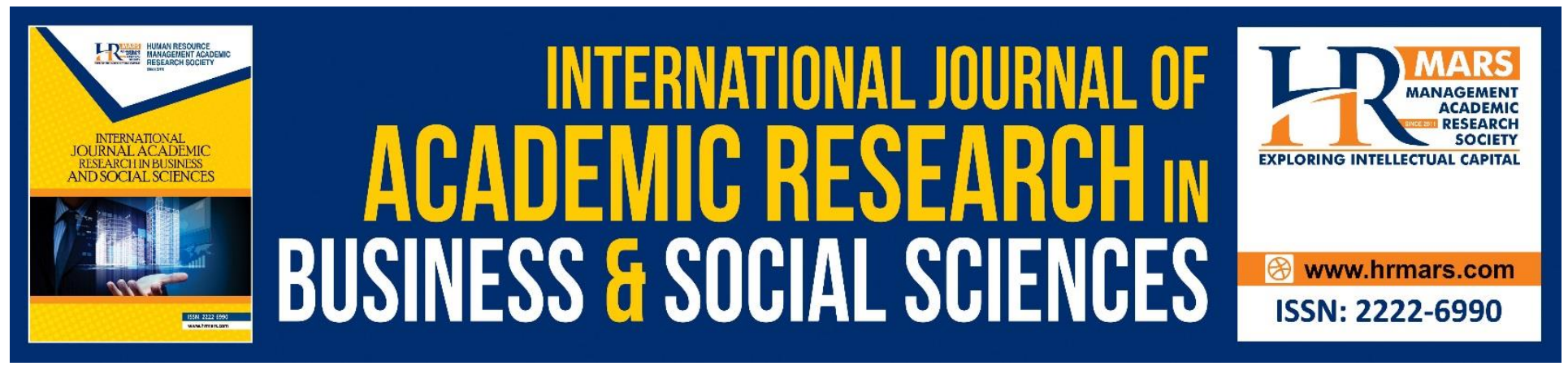

\title{
Factors of Facebook Usage Among Malay Adults
}

\author{
Mohammad Nurhafiz Hassim, Mariah Muda, Massila Hamzah
}

To Link this Article: http://dx.doi.org/10.6007/IJARBSS/v8-i12/5442

DOI: $10.6007 /$ IJARBSS/v8-i12/5442

Received: 30 Nov 2018, Revised: 24 Dec 2018, Accepted: 01 Jan 2019

Published Online: 08 Jan 2019

In-Text Citation: (Hassim, Muda, \& Hamzah, 2018)

To Cite this Article: Hassim, M. N., Muda, M., \& Hamzah, M. (2018). Factors of Facebook Usage Among Malay Adults. International Journal of Academic Research in Business and Social Sciences, 8(12), 2315-2325.

\section{Copyright: (c) 2018 The Author(s)}

Published by Human Resource Management Academic Research Society (www.hrmars.com)

This article is published under the Creative Commons Attribution (CC BY 4.0) license. Anyone may reproduce, distribute, translate and create derivative works of this article (for both commercial and non-commercial purposes), subject to full attribution to the original publication and authors. The full terms of this license may be seen at: http://creativecommons.org/licences/by/4.0/legalcode

Vol. 8, No. 12, 2018, Pg. 2315 - 2325

Full Terms \& Conditions of access and use can be found at http://hrmars.com/index.php/pages/detail/publication-ethics 


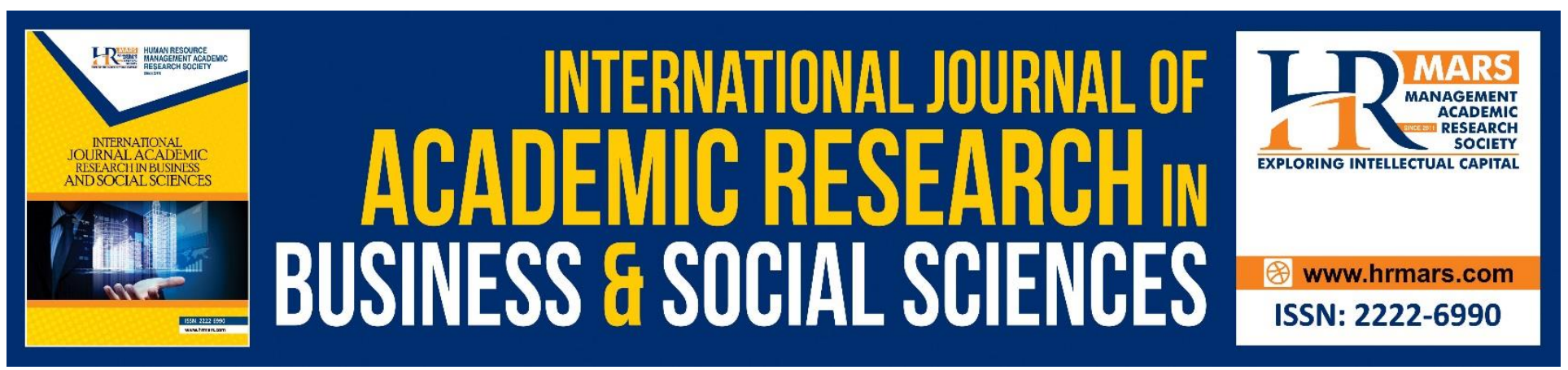

\title{
Factors of Facebook Usage Among Malay Adults
}

\author{
Mohammad Nurhafiz Hassim¹, Mariah Muda², Massila Hamzah³ \\ Faculty of Communication and Media Studies, UiTM Shah Alam, Selangor, Malaysia
}

\begin{abstract}
At present, Facebook is not only used by the teenagers, but it is also rather popular among the adults who use the social networking application with a variety of factors and specific goals. This study, therefore, aims to examine the factors that contribute to the increasing usage of Facebook among Malay adults in Malaysia. To carry out this research, a qualitative approach involving in-depth interviews with selected informants comprising adults aged 35 years and above was employed. From the analysis of the interviews, the findings showed that several factors caused the Malay adults to use Facebook. These factors are as following: (i) Facebook is used because there is a variety of interactive games available, (ii) Facebook is used in the job sector, (iii) Facebook has become a medium in starting an online business, (iv) Facebook constantly updates its application technology system and (vi) Facebook is easy to access.
\end{abstract}

Keywords: Factors, Usage, Malay adults

\section{Introduction}

Technology in this century is growing rapidly and becoming increasingly sophisticated. Its development is great for people around the world to follow. The degree to which communications technology has developed or is developing can be experienced when a new software or gadget is developed almost every day. Social media is an example of developing technology of this century. It is a very important communications tool which undeniably has a major role in both social and business relationships. In the current era of globalisation, new media are seen more dominant than traditional media such as print media, electronic media, broadcast media, and other interpersonal media. Therefore, the society in this era has witnessed a shift in paradigm as they took advantage of the cutting-edge technology they have in their daily lives. Clearly, the society no longer lives in small groups or clusters; in fact, the earlier community of people associated with the influence of mass media is diminishing and being replaced by the structure of the network society which witnessed the face-to-face communication being replaced by an intermediary communication (Mustafa \& Hamzah, 2011).

The advent of Facebook social media which was launched on February 4, 2004 by Mark Zuckerberg, a Harvard student, was initially restricted to students from Harvard College only. In February 2004, Zuckerberg launched Facebook and the name was taken from forms distributed to 
new students. Within the course of 24 hours after the launch, 1200 Harvard students enrolled, and within a month, almost half of the Harvard baccalaureate student population had a profile on the site (Er, Mustaffa, \& Salman, 2014). Facebook membership is free of charge and its profits are derived from advertisements on the site. In social networks, friends are the most powerful and influential people. This is because friends are people that we have already known and built close relationships (Er et al., 2014), thus, allowing users or members to form impressions or maintain relationships, and acquire new relationships (Tong, Heide, Langwell, \& Walther, 2008).

The increase in the average Facebook usage in Malaysia to 25.08 million users, representing $79 \%$ of the population of Malaysia (Khalil, 2018), has caused a widespread social problem to arise following the uncontrolled use of Facebook (Ismail, Ahmad, \& Nasir, 2015). In fact, social problems such as the collapse of the marital lives among Malay adults are in the increase, particularly among the Muslim Malays. This is as evidenced by the Kosmo Press which reported a distressing increase in divorce cases in Malaysia with a total of 274,000 divorced couples in the last six years (Kosmo Online, 2018). Due to the fact that the Malays are reported as among the highest in this problem, this study examines the factors that motivate Facebook usage among Malay adults in Malaysia today.

\section{Literature Review}

A previous study found that Facebook is being used by the global community today because of the simple and user-friendly features that are available on Facebook such as 'status update' which allows users to update their status or reply to their status immediately. Within seconds following the status update, a display of user status would appear in the news feed (Harter 1999, in Schwartz, 2010). Boyd \& Ellison (2008) also pointed out that Facebook users are also more likely to think about what needs to be updated in their Facebook accounts, for example, updating in their profile section using features such as "About Me" and "Update Status". This, indirectly, creates opportunities for self-presentation through personal profiles and enables users to showcase personal information such as videos, pictures and status. In this way, they can choose and upload images that are perceived to have physical attraction and hide unwanted things in their Facebook accounts (Ellison et al., In Kim, 2013). According to Donath \& Boyd (2004), Facebook also serves as a platform to maintain and expand the existing network of connections. This is because in the virtual world, the relationship is not limited as compared with a face-to-face relationship. If there exists a gap in the offline face-to-face communication, online social interaction can help to fill the void (Wellman, 2001). In the meantime, Boyd \& Ellison (2007) found that Facebook communication is more likely to maintain existing relationships between users and not with strangers. Studies conducted by Subrahmanyam, Reich, Waechter, \& Espinoza (2008) and Pempek, Yermolayeva, \& Calvert (2009) found that Facebook is used to connect with known friends and that the relationship is then maintained through the Facebook network. However, most users use Facebook to preserve or strengthen their existing offline relationships (Ellison, Steinfield, \& Lampe, 2007).

This study uses the usage and gratification (UGT) theory to focus on individual use and media selection (Katz, Gurevitch, \& Haas, 1973) to examine the factors influencing Facebook usage among Malay adults. Basically, the uses and gratification theory focuses on individual behavior that can be heavily influenced by the needs and interests of an individual rather than solely influenced by the characteristics of the media contents. Individuals acquire a lot of knowledge, which enables them to 
use the media as a reference.

\section{Uses and Gratification Theory (UGT)}

Musa et al., (2015), in their study that explored the current function of the Uses and Gratifications Theory in the use of social media among students, found that the majority of respondents use social media to communicate, collaborate, share news, research, express opinions, maintain relationships, and make friends from other countries. Meanwhile, research conducted by Papacharissi \& Rubin (2000) using their Internet usage scale has found five main motivations to use the Internet, namely utility, pass time, information seeking, convenience and entertainment. Whereas Parker \& Plank (2000) identified three factors, which are friendship and social needs, learning needs, and happiness and relaxation needs.

In general, engagement in social media, especially Facebook, is a new phenomenon experienced by people, which is seen to have implications on the communication and interaction processes as well as to provide them with satisfaction. Therefore, Uses and Gratification theory is the ideal theory to identify and analyse the reasons why people use social media. Moreover, the use of the UGT in social media research is very important because the form of this new mass media is rather new as compared with the old media. Unlike the traditional media that provides users with limited choices, this new media offers various new choices to the users. Hence, this theory will help clarify the needs of the users and the gratifications they achieve using the new media.

Therefore, the purpose of using the uses and gratification theory in the current study is to guide me to know the reasons behind Malay adults using the Facebook application and what motivates them to use this application. According to Park, Kee, and Valenzuela (2009) and La Rose and Eastin (2004), they found the major UGT in relation to social media users, which is socializing, entertainment, selfstatus seeking, and information (Gallion, 2009). Apart from these studies, I would like to see how Malaysians use Facebook to maintain relationship, find new friends and build social interactions between them. Furthermore, using Facebook is an opportunity for Malay adults to share opinions and emotions via status updates, emoticon messages and videos. Haridakis and Hanson (2008) suggested that social media such as YouTube could motivate social means (Gallion, 2009).

In sum, the uses and gratification theory is used to guide this study because it was related with the topic of Facebook usage. We could see that social media such as Facebook can be used for a variety of reasons and can potentially provide some gratification users, including the ability of social networks, micro blogging capabilities, information dissemination, information searching, maintenance of relationships, news reports, and advertising potential (Ballard, 2011). The use of this theory in the current study is to understand the motivations of people using Facebook and also the satisfaction they get from using the application.

\section{Methodology}

The study was conducted using a qualitative method to understand the particular phenomenon or being studied. Research use qualitative methods to gain enlightenment, understanding of phenomena and extrapolation to the same situation (Golafshani, 2003). The phenomenology approach, on the other hand, is used as a guide to conduct a research on a phenomenon that is taking 
place which, in the context of this study, is the use of social media especially Facebook among Malay adult users. Creswell (1998) argued that phenomenology studies describe the meaning of life experiences for individuals regarding the concepts or phenomena studied. The concept of phenomenology is to understand what people experienced from the first-person point of view, that is, from the people with that experience (Sass, 2014; Hahn, 2009; Hajaroh, 2009).

The interview was conducted with several selected informants based on purposive sampling technique. Patton (2002), in Merriam (2009), explained that a purposive sampling is based on the assumption that researchers want to know, understand, and gain comprehension. Therefore, the chosen sample must be the most appropriate to be studied based on the purpose of the study. 15 informants were carefully selected for this study. The selected informants were Malay adults over 35 years old since this study focuses only on Malay adults with mature minds in decision making, actively using Facebook and living in the Klang Valley, due to limited time constraints. The informants were also informed that the interview process was intended to collect data for the purpose of this study. The analysis of the interviews was carried out using the Atlas T.I. software to facilitate the processes of organizing and building the themes. Prior to that, the researcher initiated the transcription process of all the speeches or words spoken by the informants during the interview process to ensure that no words were removed from the analysis. Meanwhile, the thematic analysis technique was used to compare the themes in this study. To ensure that all personal information of the informants is preserved and kept confidential with anonymity, researchers have labeled them as Informant 1 to Informant 15. In addition, to ensure the validity of the findings in this study, the quotations of each spoken word from the informants are very important and cited in this article.

Therefore, following a few steps in this qualitative process, researchers can have a better and deeper understanding of the factors that encourage Malay adults to use Facebook.

\section{Analysis \& Discussion}

There is a wide variety of social media in existence today, and among them is Facebook. Facebook is popular all over the world, including Malaysia as it is one of the most frequently used communication mediums (Mahmud \& Omar, 2013). New additions and upgrades make Facebook increasingly popular among its users across the globe. This includes those who are already adults and have families, as these groups are also not excluded from the transformation of social media technology today. Facebook is popular due to its ease of access, making this application 'user-friendly' for everyone to use.

This study focuses on Malay adults to examine the factors behind their increasing Facebook usage. For this research, several new themes were obtained through the analysis of the interviews. The interviews conducted with the 15 selected informants have found several different findings than the past studies. The following are the themes that emerged after the analysis.

\section{Playing Games}

During the interview, some informants mentioned that the factor that caused them to use Facebook is to play games in the smartphone application. They said that they have played games on the app but not as frequent as before. This is due to the increase in age; but, they also felt excited when they shared games on their mobile phones with others. 
INTERNATIONAL JOURNAL OF ACADEMIC RESEARCH IN BUSINESS AND SOCIAL SCIENCES

Vol. 8, No. 12, Dec, 2018, E-ISSN: 2222-6990 @ 2018 HRMARS

"Back then we used to like playing games on $F B$, like share request, when games when a thing on FB, play it every day like Candy Crush for example, so can ask for lives and all. Nowadays I don't play it anymore maybe because of the age factor, so I'm not into games and all'.

(Informant 8/ 23 Sept. 2017/ 4.00 P.M.)

"There was a time when we have games that need to request lives from friends who play the same game, but now I don't play it anymore due to age factor plus we don't want to play the games like the kids nowadays".

(Informant 12/ 19 Oct. 2017/ 2.00 P.M.) Informants in this study also mentioned that, at some point, they were also obsessed with the games on the smartphone.

"I used to play games, and I got very addicted, I want to see what will happen every day. Hence, we would not realize that we've been playing for an hour or two, I used to feel the obsession with games, because, during free time, I don't know what to do, I will launch FB and play the games, that time I was super addicted, I didn't know what to do, I just love games so much, after that I don't play games anymore, only to seek information'.

(Informant 11/ 17 Oct.2017/ 2.00 P.M.)

Informants in this study also appeared to know of the game 'Mafia Wars' on Facebook when they explained the specific levels to be achieved and that it allowed them to sell the game to other interested people.

"Back then it was all about games, what game did I play? Oh Mafia Wars, played that a lot, sometimes I play Poker and all. Now I no longer play but I see a lot of people who play. Some only go on Facebook and play Mafia Wars at the highest level and sell to interested buyers, some people make money out of it".

(Informant 1/ 27 Aug. 2017/ 8.00 P.M.)

Based on this analysis, it can be concluded that the adults are also no exception to playing games on Facebook. In fact, the informants in this study are also familiar with a game that is usually known only to teenagers. Therefore, this study has found a new insight, that the factor of Facebook usage among Malay adults is to play games on Facebook.

Work Activity Purposes

Next, informants said that they used Facebook for their work purposes. Some of these informants use Facebook at their workplace where Facebook is a source of information for them to know something quick and fast compared to the traditional media. Those who work in the customer service sector believe that Facebook is a medium of interaction with their customers to communicate other than the telephone line. Some organizations use Facebook to introduce their products to the public. Broughton, Higgins, Hicks, \& Cox (2009), in their argument, stated that the productivity of an organization exists due to the social media being used, replacing email, messages and telephone.

"In terms of works, I have been working in a field that requires daily updates. It's not about me checking on my friends' statuses or whatnot, but more towards checking on the news. Trending, human interests, something related to me, related to my field of work and not unrelatable things. I only check on things that relate to my work only."

(Informant 9/ 4 Oct. 2017/ 1.00 P.M.) 
INTERNATIONAL JOURNAL OF ACADEMIC RESEARCH IN BUSINESS AND SOCIAL SCIENCES

Vol. 8, No. 12, Dec, 2018, E-ISSN: $2222-6990$ @ 2018 HRMARS

"There are pros and cons, sometimes it is convenient for people to see who we are without us having to over-announce ourselves digitally, sometimes people can directly respond if we have companies where people can read the feed and give negative comments, like negative comments about products. Hence, we can take it positively, but for the comments that are bad, sometimes the rumours won't be good. Instead of us overcoming it, we shouldn't take the rumours into account because it is all coming from people's mouth, we control them like blocking them. We, as admins, answer the questions safely but it is based on facts."

(Informant 15/ 1 Nov. 2017/ 8.00 P.M.)

Therefore, it can be concluded that the use of Facebook is now widespread not only to communicate, but also to be used in the work sectors. It can be viewed here that the significance of social media technology is undeniable. This can be portrayed through the media of ecology theory founded by Marshall McLuhan who stated that the society relied vastly on media technology, and indicated that the media as a tool containing technology and communication systems where humans interact with each other and becomes a bridge of their physical, biological, cultural, social and economic environments (Logan, 2016).

\section{To Do Online Business}

Previous studies have shown empirically that businesses are now more focused on online platform as it is said to provide multi-fold profits and that the marketing and promotion are more effective than the usual methods. In a previous study, it was stated that using the method of promoting product on Facebook can help disseminate the latest information on a promotion and the information will reach users via Facebook (Caers, Feyter, Couck, Stough, Vigna \& Bois, 2013).

"Other than owning a personal FB account, online business people can create their own business page where the Home button will create like my 'Cattleyn Flower Tea', it can be created and promoted there, there will be a page for business."

(Informant 5/ 8 Sept. 2017/ 8.00 P.M.)

"I do have it before, like pre-loved items, there was someone back then, she's a mother, like some items from her mother which can be used and have the quality. If we see it and think it's beautiful, we'll purchase it. In fact, I myself was a businessman on FB, but that was 4 years ago."

(Informant 13/ 25 Oct. 2017/ 3.00 P.M.)

The existence of Facebook in this century not only enables online communication, but it also gives people the opportunity to generate income by selling items online using this medium without having to sell them in stores or shopping centers. Therefore, it can be concluded that adults use Facebook for the purpose of doing business online as it is more effective, easier, and faster.

\section{Time Fulfilling}

The following theme discovered in this study is using Facebook as a mean to fulfil time. It can be time fulfilling by opening applications, reading and be entertained on Facebook.

"Facebook provides tranquillity like when you're waiting for someone, you can open Facebook while doing so. Also, you can open Facebook while doing your cycling workout."

(Informant 1/ 27 Aug. 2017/ 8.00 P.M.) 
INTERNATIONAL JOURNAL OF ACADEMIC RESEARCH IN BUSINESS AND SOCIAL SCIENCES

Vol. 8, No. 12, Dec, 2018, E-ISSN: 2222-6990 C 2018 HRMARS

"It occupies time so you don't feel bored."

(Informant 4/ 5 Sept. 2017/ 8.00 P.M.)

"Spending an hour a day is more than enough for me. An hour because I only use it for important matters, there's no need to use it for stalking purposes and other unbeneficial things. Don't need to be too long."

(Informant 5/ 8 Sept. 2017/ 8.00 P.M.)

Here, we can clearly observe that the use of Facebook provides fulfillment of free time for someone who is waiting for an individual or seeking for information, they can easily do so just by going to certain pages on Facebook without wasting time to explore other websites because anything related to current issues can be viewed on Facebook.

Various Apps on Facebook

The existence of a variety of applications on Facebook captivates users to use and explore the number one social media. A feature that was introduced in February 2017, which is live streaming through 'Facebook Live', enables users to invite friends on Facebook to communicate in 'live' mode (Aman, 2017).

"Because Facebook has a lot of things, so I don't want to compare it with IG, but Facebook does have the same feature with IG, means all in one, so from there we have live, we have news, share, likes, read, online news and all, there's Astro Awani, rotikaya, all of the daily use that I use. Other than using Facebook, games and movies".

(Informant 2/ 29 Aug. 2017/1.00 P.M.)

"Facebook now has the 'share memories', which have been recorded previously, and friends can be tagged. I like that because it brings back old memories with my friends. It can also be shared afterwards, too. But I won't share certain things that I only enjoy for myself that is only for my own information."

(Informant 6/ 22 Sept. 2017/ 6.00 P.M.)

The existence of various new applications on Facebook indirectly increases its usage to the optimum level with the existence of 'Facebook Live' that allows users to not only watch any live show on Facebook, but they can also chat together with friends on Facebook. Besides the 'live' concept featured on Facebook, other applications are also interesting and cannot be taken lightly as the informants in this study also use apps such as 'share memory' which is an application created to recall memories made from the time they were on Facebook.

Easy Access

It is undeniable that most adults use Facebook because it is easier to access. Commencing on this matter, Facebook is more popular and gaining more members in the process. According to a statistics in 2017, the number of people signed up for Facebook rose to 11.9 billion compared to that in 2016. It has been said that this amount will rise to 12.75 billion in 2018 (Statisca, 2017). This proves that Facebook is easy, fast and convenient to be used. Even adults are not exempted from using Facebook these days. This can be proven with the statements made by the informants in this study: 
INTERNATIONAL JOURNAL OF ACADEMIC RESEARCH IN BUSINESS AND SOCIAL SCIENCES

Vol. 8, No. 12, Dec, 2018, E-ISSN: $2222-6990$ C 2018 HRMARS

"It is quite easy like even if you just started using it, you can explain to others even for old people, mothers and fathers also can use it quickly."

(Informant 1/ 27 Aug. 2017/ 8.00 P.M.)

"FB is easy to use because we already have it installed on our phones. Regardless of where we are, as long if there's Internet connection, we can access FB. We can still get connected with our families if we go overseas, like with video calls and all."

(Informant 8/ 23 Sept. 2017/ 4.00 P.M.)

Hereby, we can conclude that the use of Facebook has been proven to be easy to access and be used anywhere as long as a good Internet connection is available. Even Facebook helps people in jobs, especially when companies practice the scheme of using Facebook social media.

\section{Conclusion}

Nowadays, Facebook is not only used by teenagers or middle-aged individuals, but its use is widespread because of the features available on the application. The analysis of the interviews with the 15 informants in this study indicate that Malay adults are not left behind in the face of global competition and the borderless world of technology. If social media was more focused on teenagers to communicate and get acquainted before, Facebook is now widely used as the findings of this study stated that Facebook is used in organizations aimed at promoting or introducing their products and companies, and even using Facebook to find information while working. Now with the diversity of Facebook apps that are always up-to-date, it gives Facebook more benefits over other social media. In addition, the application is quite easy to use, making Malay adults feel comfortable using the social app. Furthermore, Facebook also serves as a place for them to fulfill their free time when used as a platform to play games in the Facebook app. So, an individual has something to do when there is a free time, especially with smartphones that are increasingly becoming sophisticated today.

Thus, Facebook usage is not limited to adolescents, but it is now widely used by Malay adults for a variety of things as well as certain factors that are different from teenagers today.

\section{References}

Hassim, M. N., Muda, M., \& Hamzah, M. (2018). Factors of Facebook Usage Among Malay Adults. International Journal of Academic Research in Business and Social Sciences, 8(12), 2315-2325. 